\title{
Changes of MicroRNA-1, -15b and -21 Levels in Irradiated Rat Hearts After Treatment With Potentially Radioprotective Drugs
}

\author{
B. KURA ${ }^{1}$, C. YIN ${ }^{2}$, K. FRIMMEL ${ }^{1}$, J. KRIZAK ${ }^{1}$, L. OKRUHLICOVA ${ }^{1}$, R. C. KUKREJA ${ }^{2}$, \\ J. SLEZAK ${ }^{1}$ \\ ${ }^{1}$ Institute for Heart Research, Slovak Academy of Sciences, Bratislava, Slovakia, ${ }^{2}$ Division of \\ Cardiology, Pauley Heart Center, Medical College of Virginia, Virginia Commonwealth University, \\ Richmond, Virginia, USA
}

Received June 10, 2016

Accepted June 24, 2016

\section{Summary}

The aim of this study was to measure expression levels of microRNAs (miRNAs) (miRNA-1, -15b and -21) in the rat myocardium after a single dose of ionizing radiation (6-7 Gy/min, total $25 \mathrm{~Gy}$ ). The rats were treated with selected drugs (Atorvastatin, acetylsalicylic acid (ASA), Tadalafil, Enbrel) for six weeks after irradiation. MiRNAs levels were measured by RT-qPCR. Irradiation down-regulated miRNA-1 in irradiated hearts. In Tadalafil- and Atorvastatin-treated groups, miRNA-1 expression levels were further decreased compared with irradiated controls. However, Enbrel increased miRNA-1 level in irradiated hearts similarly to that in non-irradiated untreated group. Increase of miRNA-15b is pro-apoptotic in relationship with ischemia. Irradiation caused down-regulation of miRNA-15b. Administration of ASA in the irradiated group resulted in the increase of miRNA-15b expression compared to non-treated controls without irradiation. After Enbrel administration, miRNA-15b levels were overexpressed compared to non-treated normal group. MiRNA-21 belongs to the most markedly up-regulated miRNAs in response to cardiogenic stress. MiRNA-21 was increased nearly 2-fold compared to non-treated hearts whereas Tadalafil reduced miRNA-21 levels (about $40 \%$ ). Our study suggests that Enbrel and Tadalafil changed miRNAs expression values of the irradiated rats to the values of nonirradiated controls, thus they might be helpful in mitigation of radiation-induced toxicity.

\section{Key words}

Irradiation • Toxicity • MicroRNA • qPCR • Heart • Treatment

\section{Corresponding author}

B. Kura, Institute for Heart Research, Slovak Academy of Sciences, Dúbravská cesta 9, 84005 Bratislava, Slovakia. E-mail: branislav.kura@savba.sk

\section{Introduction}

Radiotherapy in the mediastinum area may often involve incidental exposure of the heart to ionizing radiation. In fact, epidemiological evidence has established a clear link between cardiovascular disease and exposure of the heart and major vessels to radiation doses (e.g. radiation therapy) (Darby et al. 2013).

Ionizing radiation may cause severe cellular damage both, directly by energetic disruption of DNA integrity, and indirectly, as a result of the formation of intracellular free radicals (Slezak et al. 2015). Radiation exposure consequences if are not intensive enough, may require longer period of time to develop (Donnelly et al. 2010).

MicroRNAs (miRNAs) are small, non-coding RNA molecules approximately 22 nucleotides in length which act as post-transcriptional regulators of gene expression. Each miRNA regulates dozens to hundreds of distinct target genes. Thus, miRNAs are estimated to regulate the expression of more than a third of human protein-coding genes (Lewis et al. 2005). To date, more than 2,500 miRNAs have been reported in humans (http://www.miRbase.org/). They play a crucial role in diverse cellular pathways. Many studies have suggested that miRNAs play a significant role in post- 
transcriptional gene regulation in irradiated cells (Templin et al. 2012, Lee et al. 2014). Moreover, miRNAs show different expression patterns in the normal and diseased heart and some data indicate that miRNA expression may represent an efficient diagnostic marker of the heart disease (van Rooij et al. 2006, Li et al. 2012).

The current strategy to prevent radiation-induced diseases is mostly based on administration of treatments with mitigation effects. Acetylsalicylic acid (ASA), well-known as aspirin, is non-selective inhibitor of cyclooxygenase-1 (COX-1) and cyclooxygenase-2 (COX-2), which prevents formation of pro-inflammatory prostaglandins and thromboxanes, thereby preventing clotting and formation of microthromboses (De Caterina et al. 1985, Perrone et al. 2010). Since formation of microthromboses was observed in irradiated rats (Slezak et al. 2014), acetylsalicylic acid can be useful as a possible drug for mitigation of radiation side effects. Atorvastatin (Lipitor) is widely used to inhibit 3-hydroxy3-methylglutaryl coenzyme A reductase (HMG-CoA) to decrease LDL. In many recent studies it was shown that Atorvastatin has also anti-inflammatory and antioxidative effects (Zhao et. al. 2005). Important is it has positive effect on endothelial function increasing expression of endothelial nitric oxide synthase (eNOS) and increasing bioavailability of nitric oxide (NO) (Laufs et al. 2000, Lefer et al. 2001, Treasure et al. 1995). Tadalafil (Cialis) is the inhibitor of phosphodiestherase 5 (PDE5 inhibitor) and beside the effect on erectile dysfunction it is used for treatment of pulmonary arterial hypertension (like sildenafil). Tadalafil prevents the degradation of cGMP by PDE5 what leads to binding nitric oxide (NO) to guanylate cyclase receptors resulting in increased levels of cGMP and in the vasodilatation (Webb et al. 1999). Tadalafil can be used for its vasodilatation effect in the lungs, because some of the applied radiation dose is absorbed by lungs too. This causes constriction of blood vessels and lung fibrosis. Enbrel (etanercept) is an inhibitor of tumor necrosis factor alpha (TNF- $\alpha)$. After irradiation inflammatory reactions develop in the organisms (Khan et al. 2013). It is supposed that inflammation arises from activation of TNF- $\alpha$, so its inhibition can be very useful in the treatment of radiation-induced disease.

In the present study, we measured the expression levels of miRNA-1, miRNA-15b and miRNA-21 in the irradiated rat myocardium exposed to a single dose of $25 \mathrm{~Gy}$. The main goal of our study was to examine whether expression of assessed microRNAs will be affected in the hearts of the irradiated rats after administration of potentially radioprotective drugs (acetylsalicylic acid, Atorvastatin, Tadalafil and Enbrel).

\section{Methods}

\section{Experimental models}

The experiments on animals were performed in accordance with the Ethics Committee of the Institute for Heart Research SAS and protocols approved by the State Veterinary and Food Administration of the Slovak Republic. We used 12 weeks old male Wistar rats $(250 \mathrm{~g}$ weight) that were purchased from Department of Toxicology and Laboratory Animals Breeding, Slovak Academy of Sciences, Slovakia. All animals were housed under standard environmental conditions and maintained on commercial rat chow and tap water ad libitum.

Forty rats were randomly divided into two groups, irradiated (IR, $\mathrm{n}=25)$ and non-irradiated $(\mathrm{C}$, $\mathrm{n}=15)$. Rats from IR group were anesthetized and irradiated by a single dose of ionizing radiation with a total dose $25 \mathrm{~Gy}$ in 6-7 Gy/min ratio to the mediastinum area using $5 \mathrm{MeV} / 1 \mathrm{~kW}$ electron linear accelerator UELR 5-1S equipped with tungsten converter to X-rays (NIIEFA St. Petersburg, RF).

Both groups were given specific symptomatic treatment for mitigation of a negative impact of irradiation - Atorvastatin (ATOR, $1 \mathrm{mg} / \mathrm{kg}$ ), acetylsalicylic acid (Aspirin - ASA, $12.5 \mathrm{mg} / \mathrm{kg}$ ), Tadalafil (Cialis - TAD, $0.25 \mathrm{mg} / \mathrm{kg}$ ) and Etanercept (Enbrel - E, $312.5 \mu \mathrm{g} / \mathrm{kg}$ ) - for six weeks after irradiation. Doses of drugs were calculated from the maximal therapeutic dose for humans in relation to the rat weights. Six weeks after irradiation animals were sacrificed. Hearts were rapidly removed, divided into atria, ventricles and septum, placed in the liquid nitrogen and stored at $-80^{\circ} \mathrm{C}$. Left ventricular tissue was used for the miRNAs assessments.

\section{Quantitative real-time PCR}

The total RNA was extracted by miRNA mini kit (QIAGEN Sciences, MD, USA). Concentration of isolated total RNA was measured by Nanodrop ND-1000 spectrophotometer (Agilent technologies, CA, USA). Ten (10 ng) of the total RNA was reverse transcribed to cDNA with TaqMan ${ }^{\circledR}$ MicroRNA Reverse Transcription Kit (Applied Biosystems, Carlsbad, CA, USA), cDNA was amplified using the TaqMan ${ }^{\circledR}$ Universal MasterMix II (Applied Biosystems, Carlsbad, CA, USA) on Roche Light cycler 480 II (Roche Applied Science, IN, USA). RT-qPCR was performed using specific 
TaqMan MicroRNA assays (Applied Biosystems, Carlsbad, CA, USA) for detection of miRNA-1 (assay ID 002064), miRNA-15b (assay ID 000390) and miRNA-21 (assay ID 000397) according to the manufacturer's instructions. Amplification data were normalized to U6 small RNA (assay ID 001973).

\section{Statistical analysis}

All values of experiments were expressed as means \pm SD. Statistical analysis was performed using one-way two-tailed ANOVA test, followed by Bonferroni post-hoc analysis (GraphPad Prism 7). A probability value less than 0.05 was considered to reflect statistically significant differences.

\section{Results}

Biometric parameters of experimental rats were measured six weeks after irradiation. The data are shown in Table 1. Irradiation decreased the body weight of rats after six weeks. A similar trend was seen in the measured blood pressure. Irradiated rats revealed lower blood pressure values than the non-irradiated ones.

Selected drugs (ATOR, ASA, TAD, E) were tested to alleviate the negative impact of radiation on rat hearts. In addition, we monitored the changes in the expression of miRNAs (miRNA-1, miRNA-15b and miRNA-21) as follows.

Table 1. Biometrical parameters of experimental rats.

\begin{tabular}{lccc}
\hline & $\begin{array}{c}\text { Body weight } \\
(\mathbf{g})\end{array}$ & $\begin{array}{c}\text { Heart weight } \\
(\mathbf{g})\end{array}$ & $\begin{array}{c}\text { Systolic blood pressure } \\
\text { ( mm Hg) }\end{array}$ \\
\hline Control $(n=3)$ & $397 \pm 13$ & $0.94 \pm 0.06$ & $90.38 \pm 32.6$ \\
C ATOR $(n=5)$ & $409.67 \pm 38$ & $1.02 \pm 0.07$ & $105.85 \pm 8.5$ \\
C ASA $(n=5)$ & $396 \pm 3$ & $1.04 \pm 0.10$ & $110.68 \pm 7.8$ \\
C TAD $(n=5)$ & $415.67 \pm 31.5$ & $1.00 \pm 0.06$ & $92.69 \pm 19.4$ \\
C E $(n=5)$ & $382.33 \pm 13.5$ & $1.05 \pm 0.09$ & $113.24 \pm 11.7$ \\
Irradiated $(n=3)$ & $322.20 \pm 31.3$ & $1.26 \pm 0.15$ & $76.44 \pm 8.4$ \\
IR ATOR $(n=5)$ & $342 \pm 27.7$ & $1.26 \pm 0.06$ & $98.43 \pm 19.3$ \\
IR ASA $(n=5)$ & $335.60 \pm 17.08$ & $1.27 \pm 0.13$ & $103.09 \pm 9.3$ \\
IR $\operatorname{TAD}(n=5)$ & $321.80 \pm 25.07$ & $1.27 \pm 0.13$ & $74.90 \pm 8.3$ \\
IR $E(n=5)$ & $379.60 \pm 33.6$ & $1.21 \pm 0.19$ & $96.55 \pm 29.7$ \\
\hline
\end{tabular}

Data are expressed as mean \pm SD. Control - rats without irradiation $(n=3), C$ ATOR - rats treated with atorvastatin without irradiation $(n=3), C$ ASA - rats treated with acetylsalicylic acid without irradiation $(n=3), C$ TAD - rats treated with Tadalafil without irradiation $(n=3), C E$ - rats treated with Enbrel without irradiation $(n=3)$, Irradiated - rats irradiated with $25 \mathrm{~Gy}(n=5)$, IR ATOR - irradiated rats treated with atorvastatin $(n=5)$, IR ASA - irradiated rats treated with acetylsalicylic acid $(n=5)$, IR TAD - irradiated rats treated with Tadalafil $(n=5)$, IR $E$ - irradiated rats treated with Enbrel $(n=5)$.

\section{MiRNA-1}

Expression of miRNA-1 was measured in rat left ventricles (LV) six weeks after exposure to ionizing radiation on mediastinum (Fig. 1). Irradiation caused a decrease in miRNA-1 in LV $(1.605 \pm 0.2206$ in irradiated animals, $\mathrm{P}=0.1165$ and $2.740 \pm 0.7375$ in nonirradiated control hearts). Treatment with ASA decreased miRNA-1 levels in irradiated hearts $(1.830 \pm 0.07024)$ to the same level as in irradiated rats without treatment. Treatment with ATOR and TAD further decreased miRNA levels (ATOR $\mathrm{C}=2.290 \pm 0.7823$, ATOR $\mathrm{IR}=1.478 \pm 0.1353, \quad \mathrm{P}=0.2241 \quad$ and $\mathrm{TAD} \quad \mathrm{C}=2.593 \pm$ $0.09684, \mathrm{TAD} I R=1.140 \pm 0.03979, \mathrm{P}=0.0001$ ). However,
E increased miRNA-1 level in irradiated hearts to the level of non-irradiated untreated group $(2.094 \pm 0.6295$ in IR $\mathrm{E}$ group, $\mathrm{P}=0.8611$ and $1.605 \pm 0.2206$ in irradiated control hearts, $\mathrm{P}=0.1165$ ).

\section{MiRNA-15b}

The expression of miRNA-15b was higher in control hearts $(0.1678 \pm 0.04371)$ as compared to the irradiated groups $(0.1460 \pm 0.01806, \mathrm{P}=0.6121)$ (Fig. 2). Treatment with ATOR had no significant effect on the expression levels of miRNA-15b as compared to nontreated irradiated controls $(0.1213 \pm 0.01037$ in IR ATOR group, $\mathrm{P}=0.5592$ and $0.1460 \pm 0.01806, \mathrm{P}=0.6121$ in 
IR C). On the other hand, administration of ASA had opposite effect on miRNA-15b expression levels $(\mathrm{ASA}=0.1200 \pm 0.002517$ in $\mathrm{C}, 0.1615 \pm 0.03175$ after irradiation, $\mathrm{P}=0.3654$ ). TAD group had comparable miRNA-15b expression levels in irradiated group $(\mathrm{TAD}=0.1300 \pm 0.001528$ in $\mathrm{C}, 0.1438 \pm 0.04934$ after irradiation, $\mathrm{P}=0.8403$ ) compared with non-treated irradiated group. Expression level of miRNA-15b in irradiated $\mathrm{E}$ group was increased more than in all other groups $(E=0.1317 \pm 0.03963$ in $C, 0.1900 \pm 0.04926$ after irradiation, $\mathrm{P}=0.4474$ ).
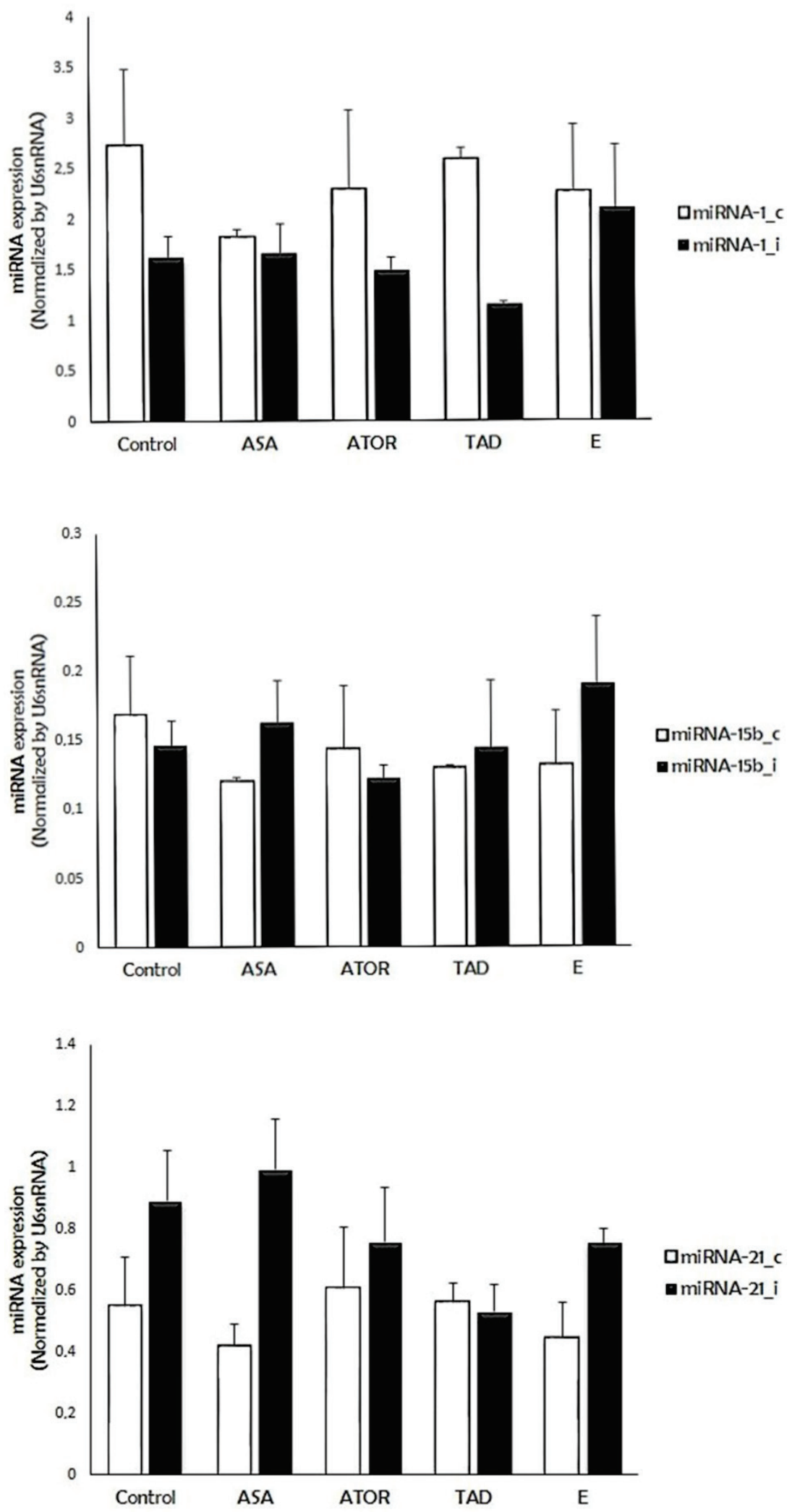

Fig. 1. MiRNA-1 expression levels in irradiated rat myocardium after treatment with acetylsalicylic acid (ASA), atorvastatin (ATOR), Tadalafil (TAD) and Enbrel (E) were expressed as mean \pm SD. White columns non-irradiated $(n=3)$, dark columns irradiated $(n=5)$.

Fig. 2. MiRNA-15b expression levels in irradiated rat myocardium after treatment with acetylsalicylic acid (ASA), atorvastatin (ATOR), Tadalafil (TAD) and Enbrel (E) were expressed as mean \pm SD. White columns non-irradiated $(n=3)$, dark columns irradiated $(n=5)$.

Fig. 3. miRNA-21 expression levels in irradiated rat myocardium after treatment with acetylsalicylic acid (ASA), atorvastatin (ATOR), Tadalafil (TAD) and Enbrel (E) were expressed as mean \pm SD. White columns non-irradiated $(n=3)$, dark columns irradiated $(n=5)$. 


\section{MiRNA-21}

Irradiation caused up-regulation of miRNA-21 in non-treated irradiated hearts $(0.8915 \pm 0.1645$ IR group, $0.5473 \pm 0.1616 \mathrm{C}$ group, $\mathrm{P}=0.1928$ ) (Fig. 3). The most effective, according to miRNA-21 expression levels, was administration of TAD $(0.8915 \pm 0.1645$ IR control group, $\mathrm{P}=0.1928$ and $0.5285 \pm 0.09128$ ATOR IR, $\mathrm{P}=0.7992$ ). Treatment with ATOR had slight effect in increasing miRNA-2 1 expression $(0.6043 \pm 0.2032$ in $C$ group and $0.7578 \pm 0.1793$ after irradiation, $\mathrm{P}=0.6051)$. Similarly, Enbrel slightly increased miRNA-21 $(0.4480 \pm 0.1159$ in $\mathrm{C}$ group and $0.7544 \pm 0.04648$ after irradiation, $\mathrm{P}=0.0266$ ). Treatment with ASA elevated miRNA-21 expression after irradiation $(0.4187 \pm 0.07044$ in $\mathrm{C}$ group and $0.9926 \pm 0.1683$ after irradiation, $\mathrm{P}=0.047$ ).

\section{Discussion}

This work was focused on the changes in the expression of miRNAs (miRNA-1, $-15 b$ and -21) in rat hearts after $25 \mathrm{~Gy}$ irradiation. The dose of $25 \mathrm{~Gy}$ was selected according to our previous screening results (not published). We wanted to achieve the maximum damage of the heart with minimal mortality in our experiments. Cytotoxicity, oxidative stress, inflammation, fibrosis and the cardiac hypertrophy represent common consequences of radiation exposure (Pathak et al. 2015, Slezak et al. 2015).

Recently, various studies showed that radiation can modulate the expression levels of the miRNAs (Chaudhry 2014, Wang et al. 2015). MiRNAs have an important function in remodeling of the heart tissue in adaptation to stressors (Romaine et al. 2015). In this study, miRNAs were used as plausible biomarkers of radiation damage and repair. MiRNAs were selected due to their known association with cardiac hypertrophy (miRNA-1), apoptosis (miRNA-15b,-21), fibrosis (miRNA-21) (Zhu and Fan 2012) and oxidative stress (miRNA-15b, -21) (Simone et al. 2009). Used miRNAs were selected based on its functions in many cardiovascular diseases and its connection with pathological processes evolving in the heart after irradiation (see results of previous experiments) (Slezak et al. 2013, 2014).

In the present study, we evaluated the changes in miRNAs expression levels in irradiated rat heart before and after administration of drugs that might be involved in symptomatology of radiation injury. In normal and irradiated rat $\mathrm{LV}$, the expression of the above mentioned miRNAs was measured after six weeks of treatment. This time period was chosen as the time when all the changes are manifested and are maximally expressed. We used selected drugs with possible mitigating effect (acetylsalicylic acid - Aspirin (ASA), Atorvastatin Lipitor (ATOR), Tadalafil - TAD and Etanercept Enbrel (E). These drugs were selected mainly due to their involvement in antioxidative, antithrombotic, antiinflammatory and cardioprotective pathways of cardiomyocytes and endothelium that is important in suppressing of the negative radiation effects.

\section{MiRNA-1 expression levels}

MiRNA-1 belongs to the most abundant miRNAs in normal rat heart tissue. Available studies showed that miRNA-1 was frequently down-regulated in various types of cardiac diseases (Duan et al. 2014). Our results showed that exposure to the radiation (single dose of $25 \mathrm{~Gy}$ ) decreased miRNA-1. Similarly Ikeda et al. (2007) reported that miRNA-1 was down-regulated in dilated cardiomyopathy and aortic stenosis. A decreased expression of miRNA-1 was observed in several models of cardiac hypertrophy and heart failure (Ikeda et al. 2009, Sayed et al. 2007). These results were also confirmed in humans. Seronde et al. (2015) found that levels of miRNA-1 were significantly lower in acute heart failure and chronic heart failure patients compared to healthy subjects.

The expression of miRNA-1 in the irradiated heart after the administration of ASA, ATOR, TAD and E is currently unknown. Our results show that treatment with ASA, ATOR and TAD had no protective effect on the heart exposed to irradiation. On the other hand, treatment with $\mathrm{E}$ increased miRNA-1 value in irradiated hearts to the level of non-irradiated controls. Thus E appears to be the most effective drug in restoring the miRNA-1 as compared to other administered drugs. These results suggest that inhibition of TNF- $\alpha$ inflammatory pathway with $\mathrm{E}$ might be very effective in irradiation injury which is supported by the fact that TNF- $\alpha$ is activated by calmodulin (Wang et al. 2012) and it is inversely correlated with miRNA-1 expression (Ikeda et al. 2009). These results indicate that calcium plays a critical role in the myocardial hypertrophy induced by TNF- $\alpha$, suggesting that the TNF- $\alpha$-induced hypertrophic response may be linked to $\mathrm{Ca}^{2+}$ homeostasis (Wang et al. 2012). 


\section{MiRNA-15b expression levels}

MiRNA-15b has its role in the cardiac development and disease (Porrello 2013). Moreover, it has been reported that the expression of miRNA- $15 b$ may be altered following exposure to various genotoxic stressors including radiation (Simone et al. 2009). In the present study, we observed that miRNA-15b was downregulated in irradiated rat hearts as compared to nonirradiated ones. Similarly, Guo et al. (2009) reported that miRNA-15b was down-regulated in rat activated hepatic stellate cells and which correlated to apoptosis by targeting Bcl-2. However, most of the studies revealed opposite effect of miRNA-15b. Up-regulation of the miRNA-15 family was observed following cardiac ischemia and heart failure (Latronico et al. 2007). In another study, Tijsen et al. (2014) showed up-regulation of miRNAs from miRNA-15 family in the overloaded heart. It was suggested that miRNA-15 family can inhibit the TGF $\beta$-pathway which is important in the development of cardiac fibrosis and hypertrophy. Quantitative real time-PCR data showed that the expression of miRNA-15a and miRNA-15b was up-regulated in mice hearts subjected to ischemia/ reperfusion and overexpression of miRNA-15b enhanced cell apoptosis (Liu et al. 2012). Rahman et al. (2014) identified miRNA-15b up-regulation in a dose- and timedependent manner in human bronchial epithelial cells (HBEC).

To our knowledge, the expression of miRNA- $15 b$ in the irradiated heart after the treatment with ASA, ATOR, TAD and E has not been reported yet. Treatment with ASA and E caused up-regulation of miRNA-15b in irradiated rat ventricles to the level of non-irradiated non-treated hearts. This indicates that ASA and $\mathrm{E}$ may protect the irradiated heart from fibrosis and hypertrophy, probably through their anti-inflammatory actions. In irradiated groups, administration of ATOR and TAD had no significant effects on miRNA-15b expression levels. These results suggest that inflammatory pathways are important in mitigating the cardiac fibrosis and hypertrophy. Protective effects of ASA and E can also be mediated through targeting $\mathrm{Bcl}-2$ gene expression, because ASA (Ding et al. 2014) and E (Malaviya et al. 2006) are pro-apoptotic as well as miRNA-15b, so they can alleviate hypertrophy and fibrosis (Slezak et al. 2015).

\section{MiRNA-21 expression levels}

Dong et al. (2014) found that miRNA-21 expression was significantly higher in cardiac fibroblasts than in cardiomyocytes. Cardiac fibrosis is an important factor involved in the development of heart insufficiency and miRNA-21 is highly expressed in fibrotic cardiac muscles (Thum et al. 2008). In the present study, we showed that miRNA-21 levels were up-regulated in the irradiated hearts compared to the non-irradiated controls. These results are consistent with the finding by Valkov et al. (2015). MiRNA-21, a well-studied miRNA in cardiac fibroblasts and fibrosis development, was increased 3.1-fold upon fibroblast activation. Halimi et al. (2014) found out that miRNA-21 level before radiotherapy was comparable with that in healthy volunteers $(\mathrm{P}=0.10)$ and increased significantly after radiotherapy $(\mathrm{P}<0.001)$. MiRNA-21 was shown to be altered under conditions of various oxidative stressors including radiation (Simone et al. 2009). Viczenczova et al. (2016) observed increased levels of miRNA-21 and total $\mathrm{Cx} 43$ protein expression in rat hearts after chest irradiation.

MiRNA-21 levels were not previously measured in irradiated rat hearts after administration of ASA, TAD, ATOR and E. Based on the obtained results, the most protective effect proved to be exerted by TAD, because it lowered miRNA-21 level to its value in untreated non-irradiated heart. Slight mitigating effect was also shown by ATOR and E.

\section{Conclusion}

MiRNA molecules are considered to be important prognostic and therapeutic factors in many diseases, including radiation-induced heart disease or heart failure. They are necessary in post-transcriptional regulation of gene expression and also in communication among cells. Based on miRNA expression levels, our results suggest that among the selected drugs, particularly Tadalafil and Enbrel changed miRNA expression values of the irradiated rats to the values of non-irradiated controls. Referring to these results we can suppose that Tadalafil and Enbrel might be helpful in mitigation of damaging effects of irradiation.

\section{Conflict of Interest}

There is no conflict of interest.

\section{Acknowledgements}

This work was supported by grants APVV-15-0376, APVV-0241-11, VEGA 2/0021/15 and partially NIH R37 HL051045. 


\section{References}

CHAUDHRY MA: Radiation-induced microRNA: discovery, functional analysis, and cancer radiotherapy. $J$ Cell Biochem 115: 436-449, 2014.

DARBY SC, EWERTZ M, MCGALE P, BENNET AM, BLOM-GOLDMAN U, BRØNNUM D, CORREA C, CUTTER D, GAGLIARDI G, GIGANTE B, JENSEN MB, NISBET A, PETO R, RAHIMI K, TAYLOR C, HALL P: Risk of ischemic heart disease in women after radiotherapy for breast cancer. $N$ Engl J Med 368: 987-998, 2013.

DE CATERINA R, GIANNESSI D, BERNINI W, GAZZETTI P, MICHELASSI C, L'ABBATE A, DONATO L, PATRIGNANI P, FILABOZZI P, PATRONO C: Selective inhibition of thromboxane-related platelet function by low-dose aspirin in patients after myocardial infarction. Am J Cardiol 55: 589, 1985.

DING JH, YUAN LY, HUANG RB, CHEN GA: Aspirin inhibits proliferation and induces apoptosis of multiple myeloma cells through regulation of Bcl-2 and Bax and suppression of VEGF. Eur J Haematol 93: 329-339, 2014.

DONG S, MA W, HAO B, HU F, YAN L, YAN X, WANG Y, CHEN Z, WANG Z: microRNA-21 promotes cardiac fibrosis and development of heart failure with preserved left ventricular ejection fraction by up-regulating Bcl-2. Int J Clin Exp Pathol 7: 565-574, 2014.

DONNELLY EH, NEMHAUSER JB, SMITH JM, KAZZI ZN, FARFÁN EB, CHANG AS, NAEEM SF: Acute radiation syndrome: assessment and management. South Med J 103: 541-546, 2010.

DUAN L, XIONG X, LIU Y, WANG J: miRNA-1: functional roles and dysregulation in heart disease. Mol Biosyst 10: 2775-2782, 2014.

GUO CJ, PAN Q, LI DG, SUN H, LIU BW: miR-15b and miR-16 are implicated in activation of the rat hepatic stellate cell: an essential role for apoptosis. J Hepatol 50: 766-778, 2009.

HALIMI M, PARSIAN H, ASGHARI SM, SARIRI R, MOSLEMI D, YEGANEH F, ZABIHI E: Clinical translation of human microRNA 21 as a potential biomarker for exposure to ionizing radiation. Transl Res 163: 578-584, 2014.

IKEDA S, KONG SW, LU J, BISPING E, ZHANG H, ALLEN PD, GOLUB TR, PIESKE B, PU WT: Altered microRNA expression in human heart disease. Physiol Genomics 31: 367-373, 2007.

IKEDA S, HE A, KONG SW, LU J, BEJAR R, BODYAK N, LEE KH, MA Q, KANG PM, GOLUB TR, PU WT: MicroRNA-1 negatively regulates expression of the hypertrophy-associated calmodulin and Mef2a genes. Mol Cell Biol 29: 2193-2204, 2009.

KHAN MA, DORMAND H, NEYSES L, MAMAS MA: Heart failure with etanercept therapy: a case report. $J$ Clin Exp Cardiolog 4: 236, 2013.

LATRONICO MV, CATALUCCI D, CONDORELLI G: Emerging role of microRNAs in cardiovascular biology. Circ Res 101: 1225-1236, 2007.

LAUFS U, GERTZ K, HUANG P, NICKENIG G, BÖHM M, DIRNAGL U, ENDRES M: Atorvastatin upregulates type III nitric oxide synthase in thrombocytes, decreases platelet activation, and protects from cerebral ischemia in normocholesterolemic mice. Stroke 31: 2442-2449, 2000.

LEE KF, CHEN YC, HSU PW, LIU IY, WU LS: MicroRNA expression profiling altered by variant dosage of radiation exposure. Biomed Res Int 2014: 456323, 2014.

LEFER AM, SCALIA R, LEFER DJ: Vascular effects of HMG CoA-reductase inhibitors (statins) unrelated to cholesterol lowering: new concepts for cardiovascular disease. Cardiovasc Res 49: 281-287, 2001.

LEWIS BP, BURGE CB, BARTEL DP: Conserved seed pairing, often flanked by adenosines, indicates that thousands of human genes are microRNA targets. Cell 120: 15-20, 2005.

LI DF, TIAN J, GUO X, HUANG LM, XU Y, WANG CC, WANG JF, REN AJ, YUAN WJ, LIN L: Induction of microRNA-24 by HIF-1 protects against ischemic injury in rat cardiomyocytes. Physiol Res 61: 555-565, 2012.

LIU L, LIANG Z, LIU Y, ZHENRONG LV, BAI J, CHEN J, WANG Y, CHEN C, WANG Y, WANG Y: MicroRNA-15b is implicated in regulating myocardial reperfusion injury by promoting apoptosis. Heart $\mathbf{9 8}$ : E315, 2012. 
MALAVIYA R, SUN Y, TAN JK, WANG A, MAGLIOCCO M, YAO M, KRUEGER JG, GOTTLIEB AB: Etanercept induces apoptosis of dermal dendritic cells in psoriatic plaques of responding patients. $J$ Am Acad Dermatol 55: 590-597, 2006.

PATHAK R, CHEEMA AK, BOCA SM, KRAGER KJ, HAUER-JENSEN M, AYKIN-BURNS N: Modulation of radiation response by the tetrahydrobiopterin pathway. Antioxidants 4: 68-81, 2015.

PERRONE MG, SCILIMATI A, SIMONE L, VITALE P: Selective COX-1 inhibition: a therapeutic target to be reconsidered. Curr Med Chem 17: 3769-3805, 2010.

PORRELLO EZ: MicroRNAs in cardiac development and regeneration. Clinical Science 125: 151-166, 2013.

RAHMAN M, LOVAT F, ROMANO G, CALORE F, ACUNZO M, BELL EH, NANA-SINKAM P: miR-15b/16-2 regulates factors that promote 553 phosphorylation and augments the DNA damage response following radiation in the lung. J Biol Chem 289: 26406-26416, 2014.

ROMAINE SPR, TOMASZEWSKI M, CONDORELLI G, SAMANI NJ: MicroRNAs in cardiovascular disease: an introduction for clinicians. Heart 101: 921-928, 2015.

SAYED D, HONG C, CHEN IY, LYPOWY J, ABDELLATIF M: MicroRNAs play an essential role in the development of cardiac hypertrophy. Circ Res 100: 416-424, 2007.

SERONDE MF, VAUSORT M, GAYAT E, GORETTI E, NG LL, SQUIRE IB, VODOVAR N, SADOUNE M, SAMUEL JL, THUM T, SOLAL AC, LARIBI S, PLAISANCE P, WAGNER DR, MEBAZAA A, DEVAUX Y; GREAT NETWORK: Circulating microRNAs and outcome in patients with acute heart failure. PLoS One 10: e0142237, 2015.

SIMONE NL, SOULE BP, LY D, SALEH AD, SAVAGE JE, DEGRAFF W, COOK J, HARRIS CC, GIUS D, MITCHELL JB: Ionizing radiation-induced oxidative stress alters miRNA expression. PLoS One 4: e6377, 2009.

SLEZAK J, BARANCIK M, RAVINGEROVA T, CARNICKA S, FRIMMEL K, FERKO M, ZIEGELHÖFFER A, KALOCAYOVA B, VRBJAR N, LAZOU A, KUKREJA RC, FULOP M, TRIBULOVA N, OKRUHLICOVA L: Novel mechanisms involved in early phase of cardiovascular injury after mediastinal region irradiation. Cardiologica Hungarica 43 (Suppl G): G24-G25, 2013.

SLEZAK J, BARANCIK M, RAVINGEROVA T, TRIBULOVA N, KURA B, LAZOU A, KUKREJA R, FULOP M, SAGATOVA A, VICZENCZOVA C, OKRUHLICOVA L: Molecular mechanisms of myocardial irradiation injury and potential prevention targets. In: Proceedings of New Frontiers in Basic Cardiovascular Research 2014: 11th Meeting of France - New EU Members, Smolenice, Slovakia, 15-18 June, 2014.

SLEZAK J, KURA B, RAVINGEROVA T, TRIBULOVA N, OKRUHLICOVA L, BARANCIK M: Mechanisms of cardiac radiation injury and potential preventive approaches. Can J Physiol Pharmacol 93: 737-753, 2015.

TEMPLIN T, PAUL S, AMUNDSON SA, YOUNG EF, BARKER CA, WOLDEN SL, SMILENOV LB: Radiationinduced micro-RNA expression changes in peripheral blood cells of radiotherapy patients. Int $J$ Radiat Oncol Biol Phys 80: 549-557, 2012.

THUM T, GROSS C, FIEDLER J, FISCHER T, KISSLER S, BUSSEN M, GALUPPO P, JUST S, ROTTBAUER W, FRANTZ S, CASTOLDI M, SOUTSCHEK J, KOTELIANSKY V, ROSENWALD A, BASSON MA, LICHT JD, PENA JT, ROUHANIFARD SH, MUCKENTHALER MU, TUSCHL T, MARTIN GR, BAUERSACHS J, ENGELHARDT S: MicroRNA-21 contributes to myocardial disease by stimulating MAP kinase signalling in fibroblasts. Nature 456: 980-984, 2008.

TIJSEN AJ, VAN DER MADE I, VAN DEN HOOGENHOF MM, WIJNEN WJ, VAN DEEL ED, De GROOT NE, ALEKSEEV S, FLUITER K, SCHROEN B, GOUMANS MJ, VAN DER VELDEN J, DUNCKER DJ, PINTO YM, CREEMERS EE: The microRNA-15 family inhibits the TGFß-pathway in the heart. Cardiovasc Res 104: 61-71, 2014.

TREASURE CB, KLEIN JL, WEINTRAUB WS, TALLEY JD, STILLABOWER ME, KOSINSKI AS, ZHANG J, BOCCUZZI SJ, CEDARHOLM JC, ALEXANDER RW: Beneficial effects of cholesterol-lowering therapy on the coronary endothelium in patients with coronary artery disease. $N$ Engl J Med 332: 481-487, 1995.

VALKOV N, KING M, MOELLER J, ZHANG P: Dynamic regulation of microRNAs in cardiac fibroblasts upon activation. FASEB J 29 (1 Suppl): 1045-1054, 2015. 
VAN ROOIJ E, SUTHERLAND LB, LIU N, WILLIAMS AH, MCANALLY J, GERARD RD, RICHARDSON JA, OLSON EN: A signature pattern of stress-responsive microRNAs that can evoke cardiac hypertrophy and heart failure. Proc Natl Acad Sci US A 103: 18255-18260, 2006.

VICZENCZOVA C, SZEIFFOVA BACOVA B, EGAN BENOVA T, KURA B, YIN C, WEISMANN P, KUKREJA R, SLEZAK J, TRIBULOVA N: Myocardial connexin-43 and PKC signalling are involved in adaptation of the heart to irradiation-induced injury: implication of miR-1 and miR-21. Gen Physiol Biophys 35: 215-222, 2016.

WANG GJ, WANG HX, YAO YS, GUO LY, LIU P: The role of Ca2+/calmodulin-dependent protein kinase II and calcineurin in TNF- $\alpha$-induced myocardial hypertrophy. Braz J Med Biol Res 45: 1045-1051, 2012.

WANG K, ZHU M, YE P, CHEN G, WANG W, CHEN M: Ionizing radiation-induced microRNA expression changes in cultured RGC-5 cells. Mol Med Rep 12: 4173-4178, 2015.

WEBB DJ, FREESTONE S, ALLEN MJ, MUIRHEAD GJ: Sildenafil citrate and blood-pressure-lowering drugs: results of drug interaction studies with an organic nitrate and a calcium antagonist. Am J Cardiol 83: 21C-28C, 1999.

ZHAO SP, WU ZH, WU J, HONG SC, DENG P: Effect of atorvastatin on tumor necrosis factor alpha serum concentration and mRNA expression of adipose in hypercholesterolemic rabbits. J Cardiovasc Pharmacol 46 : 185-189, 2005.

ZHU H, FAN GC: Role of microRNAs in the reperfused myocardium towards post-infarct remodelling. Cardiovasc Res 94: 284-292, 2012. 